\title{
Static Softening Behavior and Modified Kinetics of Al 2219 Alloy Based on a Double-Pass Hot Compression Test
}

\author{
Lei Liu ${ }^{1,2, *(\mathbb{D})}$, Yunxin $W u^{1,2, *}$, Hai Gong ${ }^{1,2}\left(\mathbb{D}\right.$, Abdulrahaman Shuaibu Ahmad ${ }^{2,3} \mathbb{D}^{\circ}$, \\ Fang Dong ${ }^{1,2}$ and Huamin Yu ${ }^{1,2}$ \\ 1 Light Alloy Research Institute, Central South University, Changsha 410083, China; \\ gonghai@csu.edu.cn (H.G.); dongfang@csu.edu.cn (F.D.); guoying623@csu.edu.cn (H.Y.) \\ 2 State Key Laboratory of High-Performance Complex Manufacturing, Central South University, \\ Changsha 410083, China; abddawn@csu.edu.cn \\ 3 Department of Mechanical Engineering, Kano University of Science and Technology, Wudil 713101, Nigeria \\ * Correspondence: Larill@csu.edu.cn (L.L.); wuyunxin@csu.edu.cn (Y.W.); Tel.: +86-1889-035-5864 (L.L.)
}

Received: 9 July 2020; Accepted: 28 August 2020; Published: 1 September 2020

check for updates

\begin{abstract}
In this paper, the static softening mechanism of a 2219 aluminum alloy was studied based on a double-pass isothermal compression test. For the experiment, different temperatures $(623 \mathrm{~K}, 723 \mathrm{~K}$, and $773 \mathrm{~K})$, strain rates $(0.1 / \mathrm{s}, 1 / \mathrm{s}$, and $10 / \mathrm{s})$, deformation ratios $(20 \%, 30 \%$, and $40 \%)$, and insulation periods ( 5 s, $30 \mathrm{~s}$, and $60 \mathrm{~s}$ ) were used. Based on the double-pass flow stress curves obtained from the experiment, the step rate expressed by the equivalent dynamic recrystallization fraction is dependent on the deformation parameters, which increases with the increase in strain rate and insulation time, while it decreases with the increase in temperature and strain. Based on the microstructure observed using electron backscattered diffraction (EBSD), the static softening mechanism of the Al 2219 alloy is mainly static recovery and incomplete static recrystallization. A new expression for the static recrystallization fraction is proposed using the reduction rate of the sub-grain boundary. The dependent rule on the deformation parameters is consistent with the step rate, but it is of physical significance. In addition, the modified static recrystallization kinetics established by the new SRX fraction method was proven to have a good modeling and prediction performance under given deformation conditions.
\end{abstract}

Keywords: Al 2219 alloy; static softening mechanism; step ratio; sub-grain boundary; static recrystallization kinetics

\section{Introduction}

The transition ring of the rocket tank is the key component that connects the fuel tanks and bearing stress, and its material selection and forming process has always been a serious challenge [1-3]. Currently, the Al 2219 alloy has been widely used as the base material of the aforementioned part, because of its high strength, good weldability, and stable mechanical properties at $-250-300{ }^{\circ} \mathrm{C}$ [4-8]. The forming of the transition ring mainly goes through technological processes such as casting, forging, and ring rolling, in which multi-pass characteristics are obviously observed, and its good performance is often improved through thermo-mechanical treatment (TMT) [9-11]. The softening phenomenon at the deformation intervals is closely related to the deformation process, and it is affected by many complex factors, which will eventually determine the microstructures and the specific performance [12]. Therefore, when enhancing the TMT process and material performance, it is of great significance to focus on the softening mechanism of the material, as well as its corresponding static recrystallization kinetic model. 
Presently, the research on static softening behavior is mainly based on double-pass thermal compression experiments [13-15], which have been widely conducted in various metals and alloys, such as Al-Zn-Mg-Cu alloys with various $\mathrm{Zr}$ additions [16], alloyed steel [17], titanium added ultra-low carbon (ULC-Ti) steel [18], 7150 aluminum alloy [19], Al-6Mg alloy [20], and vanadium micro-alloyed high manganese austenitic steels [21]. The reports on static softening mainly focus on the softening mechanism and kinetics modeling. For the mechanism part, Z. Jin et al. [22] found that meta-dynamic recrystallization (MDRX) and static recrystallization (SRX) occurred during the deformation interval of the AZ31 alloy. M. Zhao et al. [23] pointed out that the softening mechanism of 300M steel is mainly static recovery (SRV) and SRX as a result of strain-induced boundary migration (SIBM) through in-situ observation. X. Xu et al. [24] explored the effect of $\mathrm{Al}$ on the recovery of low-density ferritic steel containing 4 mass $\%$ aluminum, and explained the phenomenon of the suppressed recovery and correspondingly the promoted recrystallization. G. Bo et al. [25] studied the static softening behavior of a $\mathrm{Al}-\mathrm{Cu}-\mathrm{Mg}-\mathrm{Zr}$ alloy under different pre-precipitated microstructures, and interpreted the double plateaus in the static softening curve as static recovery, static precipitation, and coarsening, as well as the complete depletion of stored energy during the preserving process. For the modeling, F. Jiang et al. [26] established an empirical static recrystallization model of a 7150 aluminum alloy based on the Johnson-Mehl-Avrami-Kolmogorov (JMAK) equation. J. Tang et al. [27] constructed a simplified static softening model of a Al-Zn-Mg-Cu alloy coupled with SRV and SRX. A. Yanagida et al. [28] proposed a formulation method for a softening fraction (SF), and established static recrystallization kinetics of plain carbon steel by reverse analysis. W. Shen et al. [29] established modified Avrami static recrystallization kinetics of $\mathrm{Nb}-\mathrm{V}$ micro-alloyed steel, which regarded the material parameter (n) as the deformation parameter dependent. Although numerous kinetics of static softening have been established, most of them are derived indirectly from stress-strain curves, and few are derived from the statistics result of the microstructures, which may lead to some deviation on the accuracy of the models.

In this paper, the static softening mechanism of the 2219 aluminum alloy based on the double-pass thermal compression test and the factors influencing it were studied. Finally, the revised kinetics for the static recrystallization was proposed and established according to the specific physical mechanisms and micrographs.

\section{Materials and Methods}

An Al 2219 alloy with the composition of Al-(5.8-6.8)Cu-(0.2-0.4)Mn-0.2Si-(0.1-0.25)Zr$0.3 \mathrm{Fe}-0.02 \mathrm{Mg}-0.1 \mathrm{Zn}-(0.05-0.15) \mathrm{V}-(0.02-0.1) \mathrm{Ti}$ (weight pct.) was utilized in this test; the base material was taken from a part that was processed via post hot forging and solid solution treatment (SST) for $4 \mathrm{~h}$. The samples were machined into cylinders with a diameter of $10 \mathrm{~mm}$ and a height of $15 \mathrm{~mm}$. The two ends of the samples were coated with boron nitride and mica in order to reduce the friction between the sample and the pressure head. The test was conducted using the Gleeble-3500 thermal-mechanical testing system, based on the process curve shown in Figure 1a. The experimental procedure was as follows: The samples were heated at the set temperatures $(623 \mathrm{~K}, 723 \mathrm{~K}$, and $773 \mathrm{~K})$ at a heating rate of $5 \mathrm{~K} / \mathrm{s}$. As the peak temperature was attained, the samples were held for $180 \mathrm{~s}$ to obtain a uniformly distributed temperature. Then the first-pass compression test was carried out using $(20 \%$, $30 \%$, and $40 \%$ ) deformation ratios and strain rates of $(0.1 / \mathrm{s}, 1 / \mathrm{s}$, and $10 / \mathrm{s})$ respectively, followed by isothermal heat preservation for a duration of ( $5 \mathrm{~s}, 30 \mathrm{~s}$, and $60 \mathrm{~s})$. Then, the metallographic samples for the microstructure examination were cut, while the second-pass compression test was performed on the remaining specimens, in which the strain rate used in the first-pass was maintained, while the deformation ratios were changed to $40 \%, 30 \%$, and $20 \%$, so that the total deformation ratios of the three samples would be the same. Water quenching was performed immediately after the second-pass thermal compression test in order to preserve the deformed microstructure for the subsequent metallographic investigations. The samples before and after the test are presented in Figure $1 \mathrm{~b}$. After compression, the samples were cut parallel to the compression direction, and the 
obtained planes were observed using the electron backscattered diffraction (EBSD) and scanning electron microscope (SEM) techniques. The samples for SEM were ground and mechanically polished, while the EBSD samples were ground and electropolished (methanol nitrate solution, voltage $20 \mathrm{~V}$, and time $50 \mathrm{~s}$ ). The data obtained from the EBSD test were processed using Channal5 software, where a high angle grain boundary (HAGB; misorientation $>15^{\circ}$ ) was represented by a thick black solid line, while low angle grain boundary (LAGB; $2^{\circ}<$ misorientation $<15^{\circ}$ ) was represented by a fine white solid line.

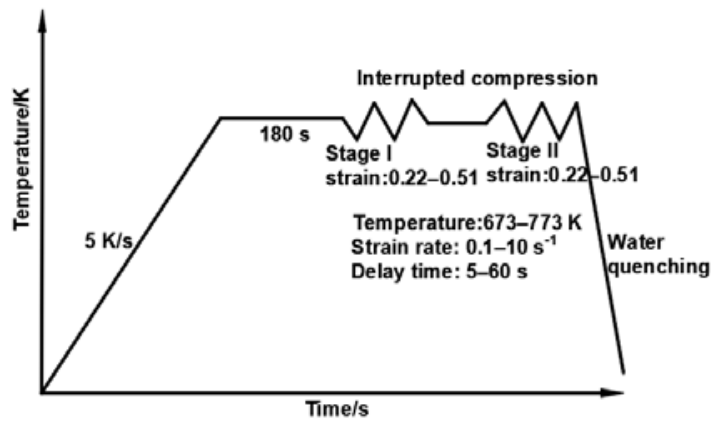

(a)

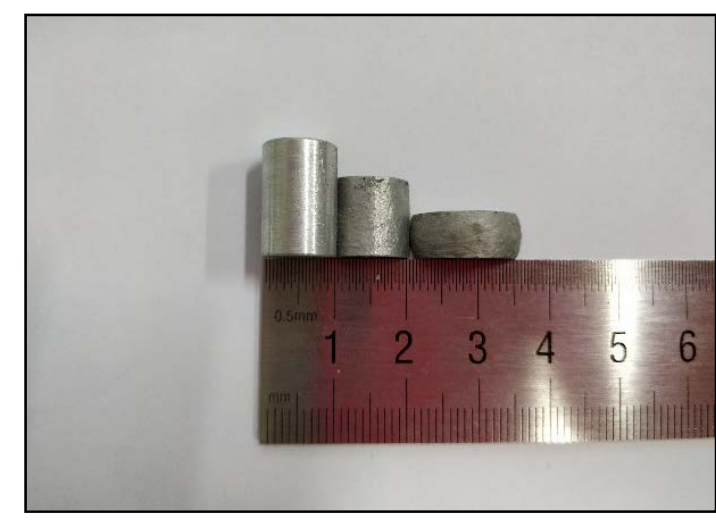

(b)

Figure 1. (a) Double-pass hot compression test; (b) the samples before and after the experiment.

The initial microstructure of the $\mathrm{Al} 2219$ alloy used before the compression test is shown in Figure 2. As presented in Figure 2a, the grain size after SST was relatively large $(>200 \mu \mathrm{m})$. Furthrmore, some grains were densely covered with a large number of sub-structures, while some grains were completely devoid of sub-structures, which indicates that SST could only restore part of the sub-structures, but could not completely eliminate it. In addition, small recrystallized grains were still left in the local area. As shown in Figure $2 b$, the LAGB had a proportion of $81.7 \%$, while the average misorientation of the initial state was $11.02^{\circ}$. It can be seen from Figure $2 \mathrm{c}$ that some precipitates clustered together and existed as chains in the aluminum matrix. From Figure $2 d$, the second phase was determined to be $\mathrm{CuAl}_{2}(\theta)$ particles using energy disperse spectroscopy (EDS) analysis.

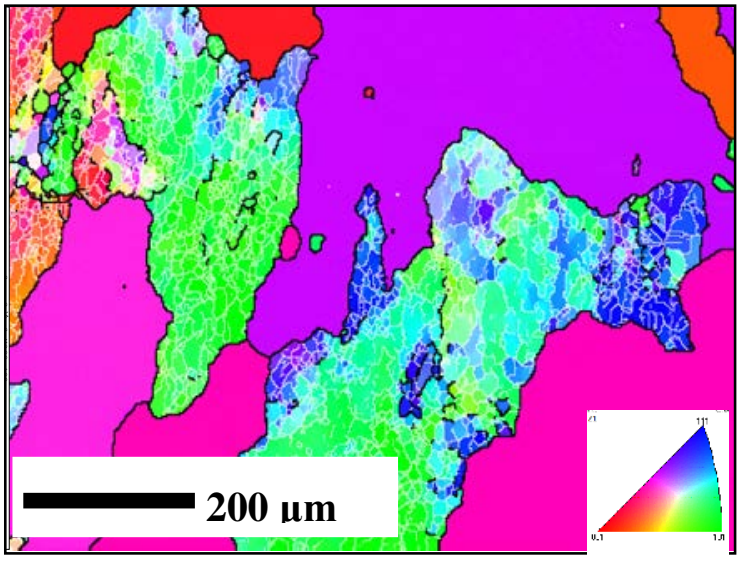

(a)

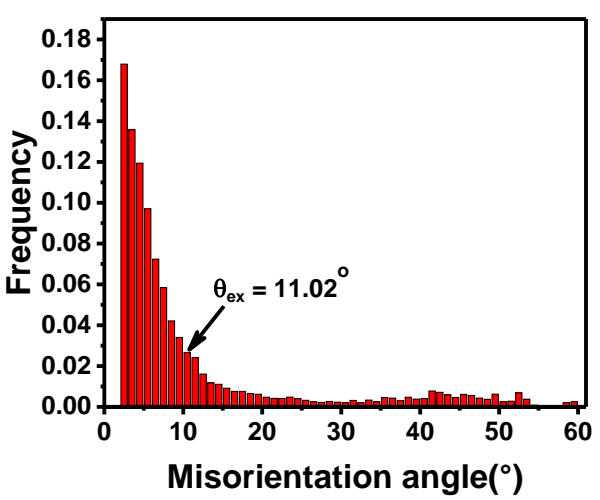

(b)

Figure 2. Cont. 


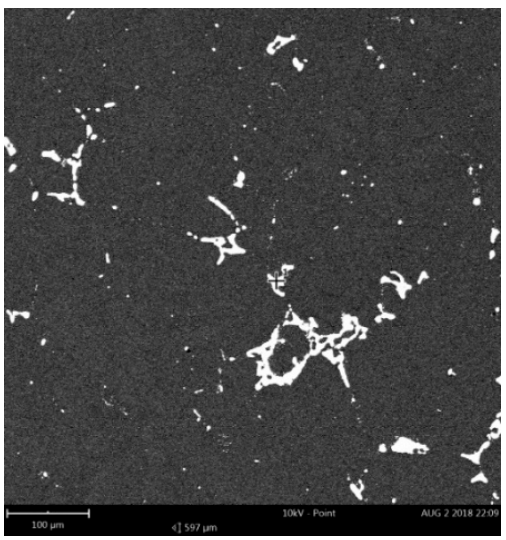

(c)

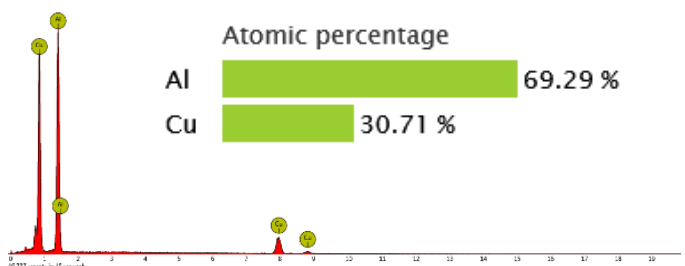

(d)

Figure 2. Initial state of the deformed samples: (a) optical microstructure $(\mathrm{OM})$ and grain boundary (GB) figure; (b) misorientation angle frequency; (c) SEM micrograph; (d) energy disperse spectroscopy (EDS) analysis.

The initial microstructure of the $\mathrm{Al} 2219$ alloy used before the compression test is shown in Figure 2. As presented in Figure 2a, the grain size after SST was relatively large $(>200 \mu \mathrm{m})$. Furthermore, some grains were densely covered with a large number of sub-structures, while some grains were completely devoid of sub-structures, which indicates that SST could only restore part of the sub-structures, but could not completely eliminate it. Also, small recrystallized grains were still left in the local area. As shown in Figure 2b, LAGB had a proportion of $81.7 \%$, while the average misorientation of the initial state was $11.02^{\circ}$. It can be seen from Figure $2 \mathrm{c}$ that some precipitates clustered together and existed as chains in the aluminum matrix. From Figure $2 \mathrm{~d}$, the second phase was determined to be $\mathrm{CuAl}_{2}(\theta)$ particles using energy disperse spectroscopy (EDS) analysis.

\section{Results and Discussion}

\subsection{Static Softening Mechanism}

\subsubsection{True Stress-Strain Curve}

The true stress-strain curves obtained from the experiment are shown in Figure 3. It can be seen that the work-hardening stage was very short (within 0.05 strain), because the initial state still contained a large number of sub-structures, so the critical point of dynamic recovery (DRV) could be reached very quickly [30]. Moreover, the flow curve showed a trend of gradually decreasing in each pass. According to the previous study of the author [31], this was because of the occurrence of the continuous dynamic recrystallization (CDRX) of the $\mathrm{Al} 2219$ alloy, where the LAGBs gradually accumulated into the HAGBs, and the average dislocation density gradually decreased [32]. Furthermore, the step phenomenon was obvious between the two compression passes. The amount of step deviation was dependent on the deformation parameters (i.e., temperature, strain rate, strain, insulation time, etc.), which indicates that the static softening occurred to different degrees during the intervals [33]. In this paper, the relationship between the flow curve and microstructure was applied to explore the static softening mechanism and quantitative description of the step phenomena. According to the previous study by the author [34], the flow stress was proportional to the (sub)grain boundary content per unit area of the material. Therefore, the decrease in flow stress indicated that the (sub)grain boundary content per unit area decreased according to the flow curve, as shown in Figure 3c, while HAGBs gradually increased at this time by the CDRX mechanism. Hence, it can be concluded that LAGBs gradually decreases in this process. As shown in Figure 3c, the peak stress of the second pass, which was approximately equivalent to the corresponding point of single-pass compression, was less than the interrupted stress of the first 
pass because of the appearance of the step phenomenon. The difference between the breakpoint and equivalent point in the single-pass curve revealed that a large number of LAGBs disappeared, and new HAGBs were generated. In other words, the occurrence of the step phenomenon proved that not only SRV occured, but SRX also appeared during the interval.

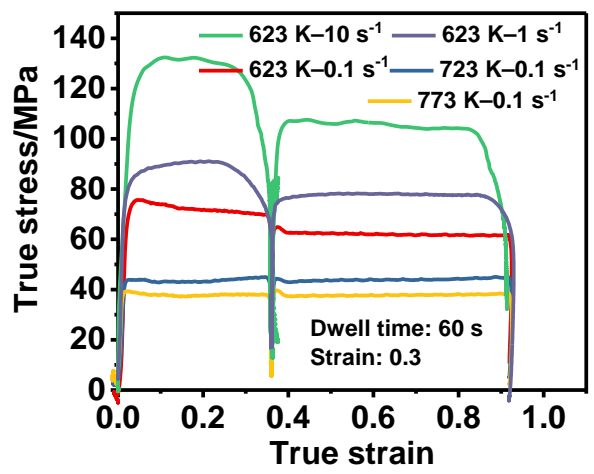

(a)

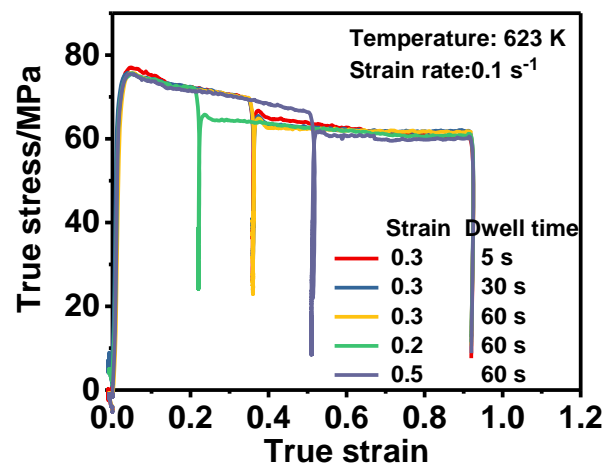

(b)

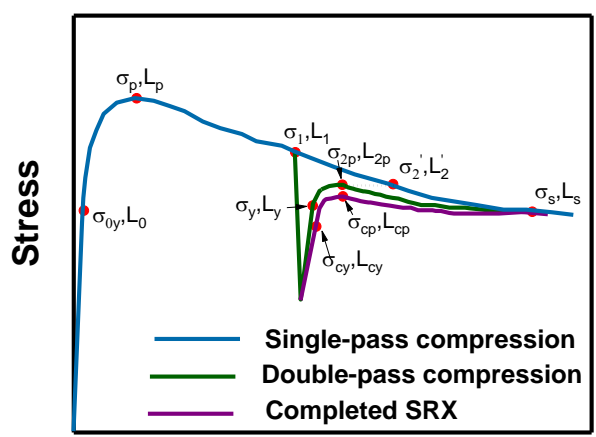

Strain

(c)

Figure 3. True stress-strain curves under the condition of (a) different temperatures and strain rates at the same dwell time and strain; (b) different dwell times and strains at the same temperature and strain rate; (c) single-pass, double-pass, and completed static recrystallization (SRX) compression.

Based on the above explanation, the equivalent CDRX fraction was proposed in order to represent the step ratio quantitatively, and the expression is shown as follows.

$$
\mathrm{X}_{\mathrm{Cq}}=\frac{\sigma_{1}-\sigma_{2 \mathrm{p}}}{\sigma_{\mathrm{p}}-\sigma_{\mathrm{s}}}
$$

where $\sigma_{1}$ is the breakpoint stress (MPa), $\sigma_{2 p}$ is the second-pass peak stress (MPa), $\sigma_{\mathrm{p}}$ is the first-pass peak stress $(\mathrm{MPa})$, and $\sigma_{\mathrm{s}}$ is the final steady-state stress $(\mathrm{MPa})$. The step ratio under different deformation conditions can be obtained by Equation (1), and the results are shown in Figure 4. In essence, the step ratio is the proportion of HAGBs generated during the interval when the whole HAGBs are generated for a complete CDRX process of a single-pass compression, which can reflect the static softening rate to some extent. Therefore, it can be seen from Figure 3 that all the step ratios are relatively small, and the maximum value is less than $35 \%$, which indicates that the static softening effect during the interval is not very significant. In addition, it is also obvious that the step ratio increased with the increase in strain rate and holding time, while it decreased with the increase in strain and temperature. This is because a large number of sub-grain boundaries were generated with an increase in strain rate. The stored energy in the sub-grain boundary could drive the movement of the sub-grain boundary 
during the thermal insulation period, resulting in the gradual accumulation of LAGBs' misorientation to produce HAGBs. In addition, prolonged thermal insulation time could promote this transformation process, and the rise in temperature could improve the kinetic energy of the atoms and speed up the dislocation movement, while the high temperature made the content of the grain boundary $(\mathrm{GB})$ reserve less, leading to the abate of the GB moving force. Evidently, the two effects were to the contrary. It can be inferred that the consequences of the reduced sub-grain boundary were greater than the activation ascension, as a result of the increasing temperature. Therefore, the static softening effect was reduced with the increase in temperature. Finally, the LAGBs contents gradually decreased with the increase in strain, leading to the weakening of the driving force during the insulation process and the static softening rate.

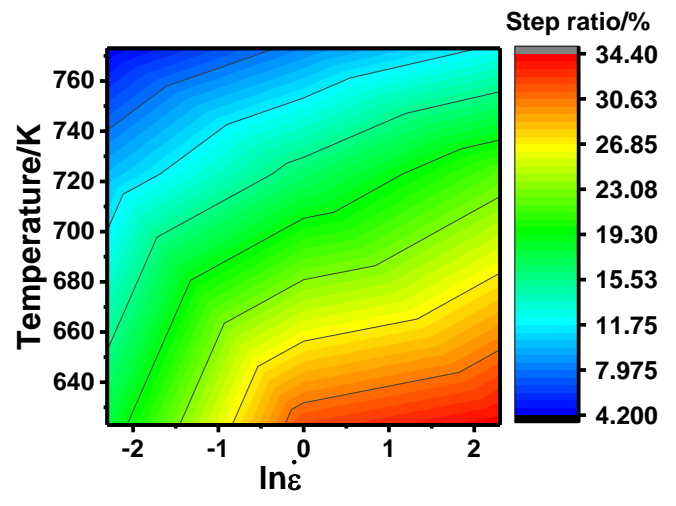

(a)

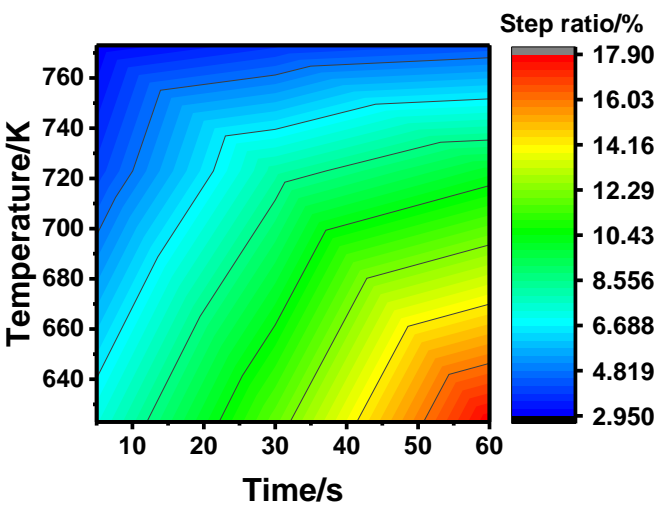

(b)

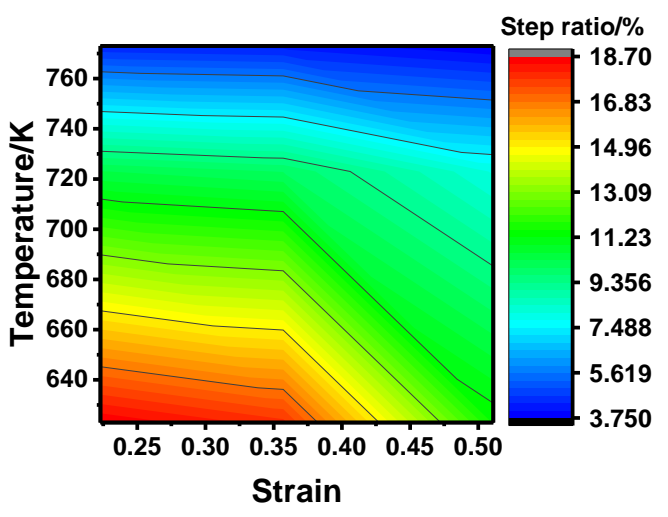

(c)

Figure 4. Step ratio under the deformation conditions of different temperatures and (a) $\ln \dot{\varepsilon}$, (b) time, and (c) strain.

\subsubsection{Microstructure Evolution}

The microstructures obtained for different deformation conditions after the thermal insulation stage are shown in Figure 5. It can be seen that the deformed grains were still covered with a large number of sub-grain boundaries, and many large sub-grains were observed, indicating that SRV caused by sub-grain boundary migration occured in the intermediate softening stage. Moreover, some scattered non-closed HAGBs were observed inside the grains, which proves that SRX also occured by the transformation of LAGBs due to the accumulation of misorientation. Apparently, the SRX ratio was very small and was also affected by the deformation parameters. In addition, the statistics of the HAGB content $\left(\mathrm{L}_{\mathrm{HAGB}}\right.$ and $\left.\eta_{\mathrm{HAGB}}\right)$, and the mean misorientation angle $\left(\theta_{e x}\right)$ under different conditions are shown in Table 1. It can be seen that the HAGB content increased when compared with the initial state, indicating that recrystallization occured, but it is not clear whether it was generated in a dynamic process or static state. Also, the HAGB and average misorientation angle under the different 
deformation conditions shown in Table 1 could not be directly compared and no conclusion could be be derived. This is because they experienced different complex evolutions under different deformation conditions, which generated different amounts of sub-grains and misorientation, meaning they had different initial states before the isothermal insulation stage. To establish the relationship between the static softening and deformation parameters, a new independent expression method was proposed, which is described in detail below.

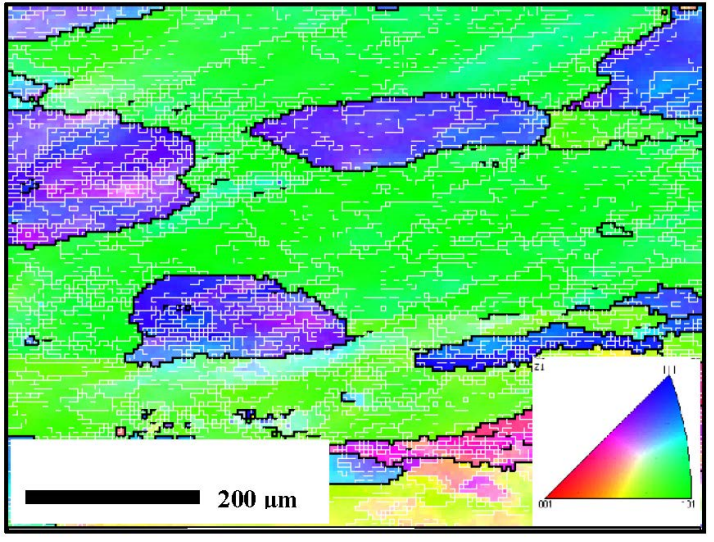

(a)

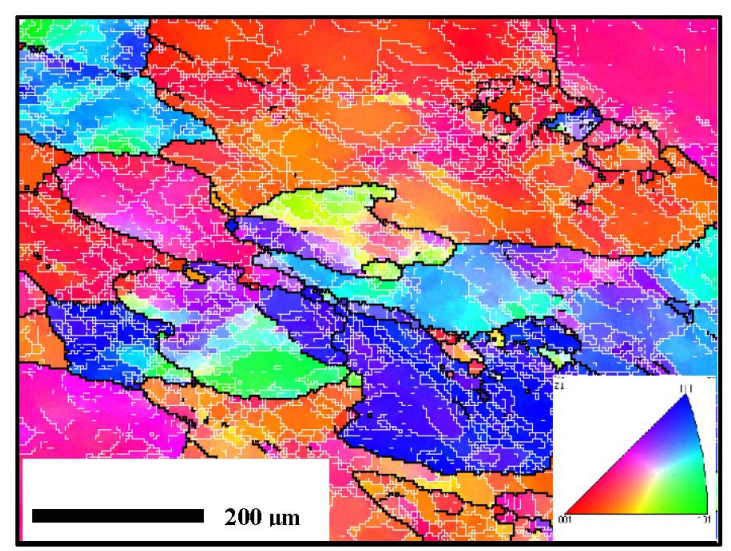

(c)

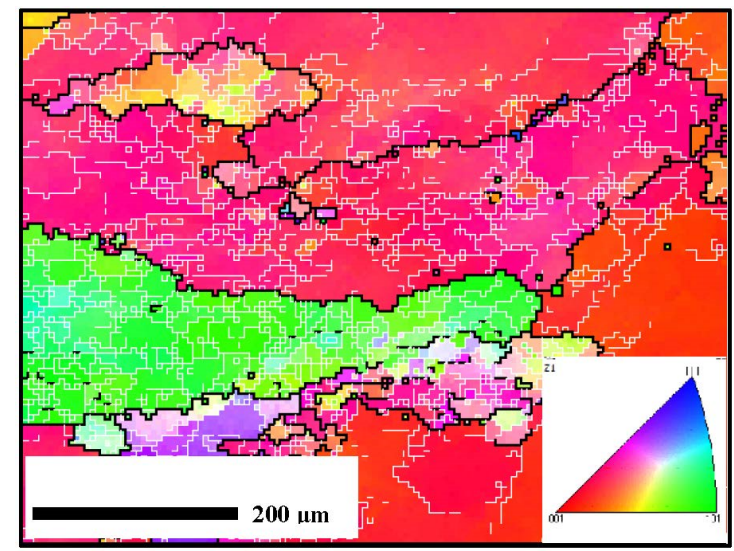

(e)

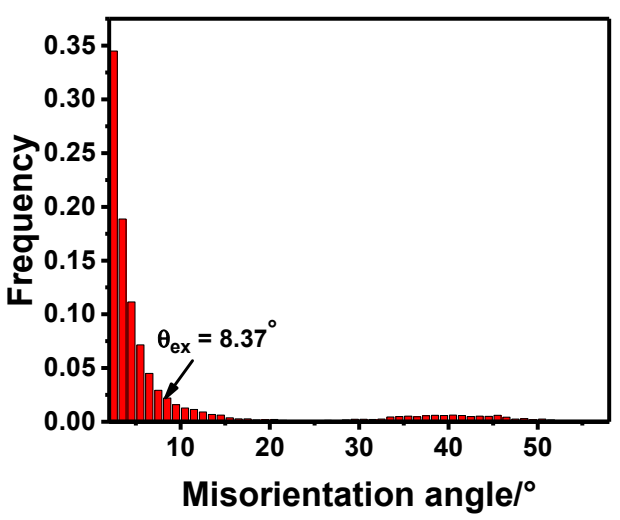

(b)

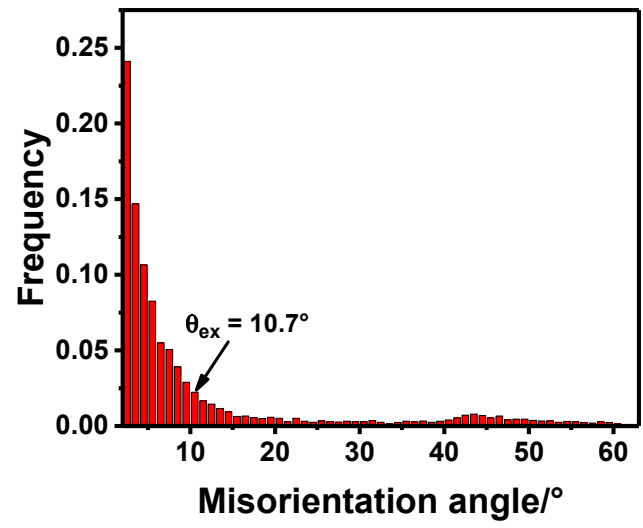

(d)

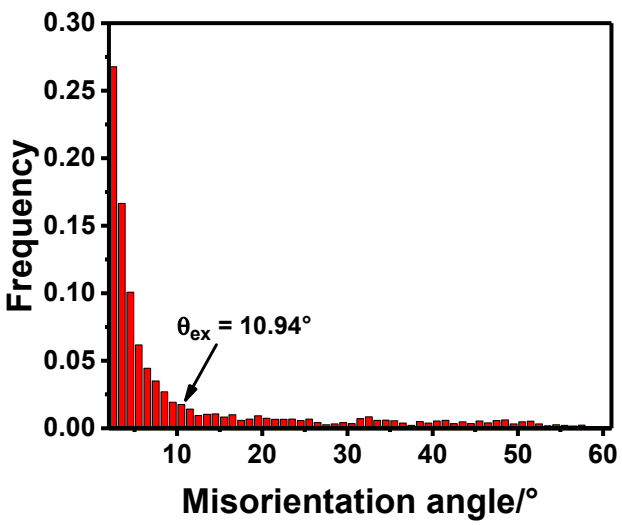

(f)

Figure 5. OM and GB figures under the conditions of: (a) $623 \mathrm{~K}-0.1 / \mathrm{s}-60 \mathrm{~s}-0.36$; (c) $723 \mathrm{~K}-0.1 / \mathrm{s}-60 \mathrm{~s}-0.51$; (e) $773 \mathrm{~K}-0.1 / \mathrm{s}-60 \mathrm{~s}-0.36$. Misorientation angle frequency under the conditions of: (b) $623 \mathrm{~K}-0.1 / \mathrm{s}-60 \mathrm{~s}-0.36$; (d) $723 \mathrm{~K}-0.1 / \mathrm{s}-60 \mathrm{~s}-0.51$; (f) $773 \mathrm{~K}-0.1 / \mathrm{s}-60 \mathrm{~s}-0.36$. 
Table 1. Material parameters under different conditions after the thermal insulation stage.

\begin{tabular}{|c|c|c|c|c|c|c|}
\hline $\begin{array}{c}\text { Material } \\
\text { Parameters }\end{array}$ & $\begin{array}{c}623 \mathrm{~K}- \\
0.1 / \mathrm{s}-5 \mathrm{~s}- \\
0.36\end{array}$ & $\begin{array}{c}623 \mathrm{~K}- \\
0.1 / \mathrm{s}-60 \mathrm{~s}- \\
0.36\end{array}$ & $\begin{array}{c}723 \mathrm{~K}- \\
0.1 / \mathrm{s}-60 \mathrm{~s}- \\
0.22\end{array}$ & $\begin{array}{c}723 \mathrm{~K}- \\
0.1 / \mathrm{s}-60 \mathrm{~s}- \\
0.51\end{array}$ & $\begin{array}{c}773 \mathrm{~K}- \\
0.1 / \mathrm{s}-60 \mathrm{~s}- \\
0.36\end{array}$ & $\begin{array}{c}773 \mathrm{~K}- \\
10 / \mathrm{s}-60 \mathrm{~s}- \\
0.36\end{array}$ \\
\hline $\mathrm{L}_{\mathrm{HAGB}} / \mu \mathrm{m}$ & $9.261 \times 10^{3}$ & $1.529 \times 10^{4}$ & $1.046 \times 10^{4}$ & $1.568 \times 10^{4}$ & $1.152 \times 10^{4}$ & $1.245 \times 10^{4}$ \\
\hline$\eta_{\text {HAGB }}$ & 0.127 & 0.226 & 0.189 & 0.275 & 0.217 & 0.176 \\
\hline$\theta_{\mathrm{ex}}$ & 8.035 & 8.37 & 8.74 & 10.704 & 10.942 & 9.171 \\
\hline
\end{tabular}

Figure 6 shows the SEM micrographs of the samples under different deformation conditions. It can be seen that the deformation parameters have great influence on the precipitation and evolution of the second phase particles. Figure $6 \mathrm{a}, \mathrm{b}$ shows the SEM results of the first pass and the second pass with the same deformation parameters, respectively. It can be seen that the total precipitates of the second phase varied slightly with the increase in strain, but the aggregate chain particles were obviously fragmented, indicating that the continuous deformation had a positive effect on the coarse $\mathrm{CuAl}_{2}$ particles fragment. Figure $6 \mathrm{~b}, \mathrm{c}$ shows the evolution of the precipitate particles at different temperatures. It is obvious that the precipitation particles decreased with the increase in temperature. This is because the solubility of copper atoms in the aluminum matrix increased with the increase in temperature, and many copper atoms redissolved into the aluminum matrix, resulting in a decrease of precipitation particles. Figure $6 c, d$ shows the precipitation phase at different insulation times. It can be seen that the overall change was not obvious, indicating that the static process had little influence on the precipitation of $\mathrm{CuAl}_{2}$ particles when the other conditions remained unchanged. Figure $6 \mathrm{e}, \mathrm{f}$ shows the morphologies of the precipitated particles at different strain rates. It can be seen that the amount of precipitated particles was similar, and the size of the $\mathrm{CuAl}_{2}$ particles decreased slightly at a high strain rate, indicating that the high strain rate was conducive to the fragmentation of precipitated particles.

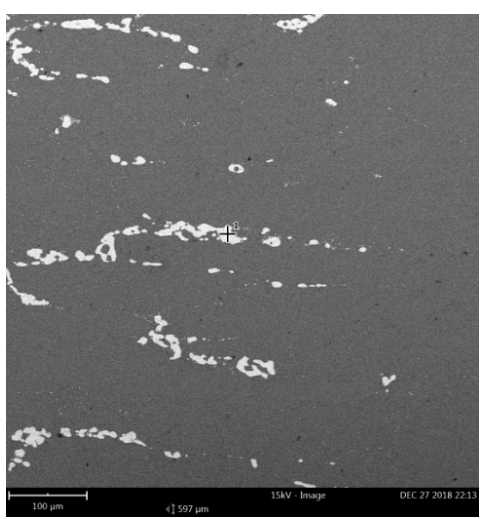

(a)

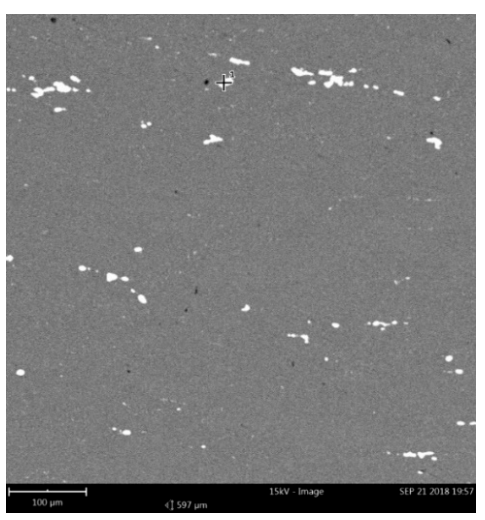

(c)

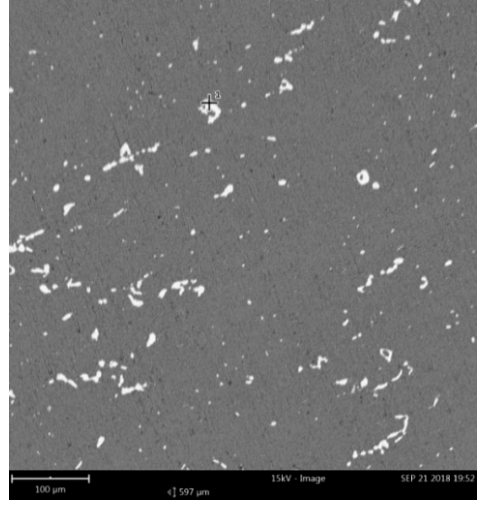

(b)

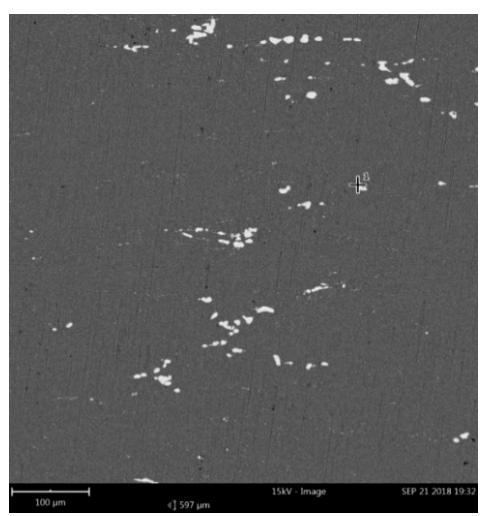

(d)

Figure 6. Cont. 


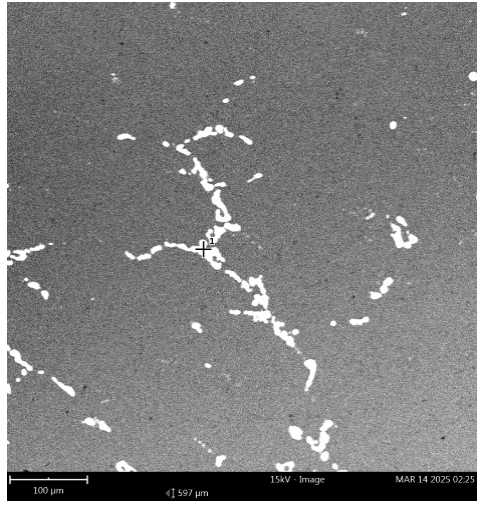

(e)

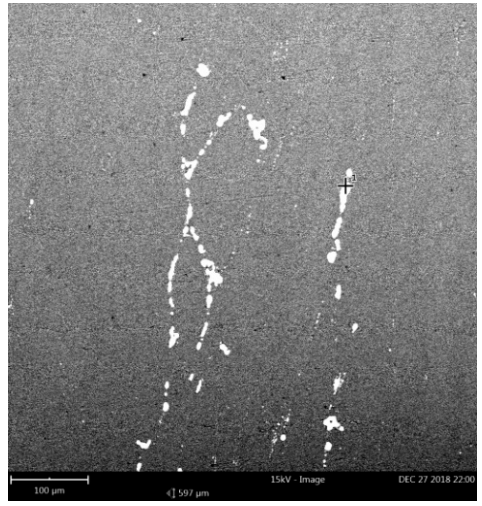

(f)

Figure 6. SEM micrographs of the deformed samples under the conditions of: (a) $623 \mathrm{~K}-0.1 / \mathrm{s}-60 \mathrm{~s}-0.36$;
(b) $623 \mathrm{~K}-0.1 / \mathrm{s}-60 \mathrm{~s}-0.9$;
(c) $723 \mathrm{~K}-0.1 / \mathrm{s}-60 \mathrm{~s}-0.9$;
(d) $723 \mathrm{~K}-0.1 / \mathrm{s}-5 \mathrm{~s}-0.9$;
(e) $723 \mathrm{~K}-1 / \mathrm{s}-60 \mathrm{~s}-0.36$;

(f) $723 \mathrm{~K}-10 / \mathrm{s}-60 \mathrm{~s}-0.36$.

From a microscopic perspective, the dislocation density and precipitated particles could be applied to qualitatively reveal the softening mechanism of SRX and its dependence on the deformation parameters. At a relatively high temperature, the dislocation density was low, which made the migration drive force of subgrain boundary insufficient, and the coarse precipitates were less, which reduced the nucleation of the particle stimulate nucleation (PSN). Therefore, the high temperature inhibited the development of the static recrystallization. At a relative high strain rate, many dislocations were generated and the precipitates' content remained almost constant, so at a high dislocation density zone, the coarse precipitates promoted the migration and growth of the subgrain boundary, thus promoting the development of the static recrystallization. At a relative high strain, the dislocation density decreased slightly because of the dynamic recovery and recrystallization, and the size of the coarse precipitates decreased and the distribution was dispersed. Therefore, the drive force of the sub-grain boundary migration was weakened and the growth process was obstructed by the dispersed precipitates, so the development of static recrystallization was decreased with the increase in strain. In addition, with the increase in insulation period, the precipitates remained constant, and the stored dislocation energy accelerated the migration and growth of the sub-grain boundaries, thus, static recrystallization could be more fully developed. Based on the microscopic mechanism discussed above, a quantitative description of the static recrystallization will be presented below.

\subsection{New Expression for Static Softening Fraction}

According to the actual effect of SRX, its fraction is usually represented by the static softening fraction (FS), which is usually represented by the function of flow stress [35-37].

$$
\mathrm{FS}=\frac{\sigma_{1}-\sigma_{\mathrm{y}}}{\sigma_{1}-\sigma_{\mathrm{cy}}}
$$

where $\sigma_{1}$ is the breakpoint stress (MPa), $\sigma_{\mathrm{y}}$ is the second-pass yield stress $(\mathrm{MPa})$, and $\sigma_{\mathrm{cy}}$ is the yield stress after complete static recrystallization $(\mathrm{MPa}) . \sigma_{\mathrm{cy}}$ is often approximated to $\sigma_{0 \mathrm{y}}$, which is significant only if the initial state is fully recrystallized. For this test and most of the commonly implemented tests, their values are not equal, because the initial state of the samples is not always fully recrystallized. Considering that, this method is no longer applicable nor the microscopic transformation mechanism of SRX. Hence, a quantitative description of SRX fraction based on the reduction rate of the LAGBs in the isothermal insulation stage is proposed and is expressed as follows:

$$
\mathrm{X}_{\mathrm{S}}=\frac{\mathrm{L}_{1_{\mathrm{L}}}-\mathrm{L}_{\mathrm{y}_{\mathrm{L}}}}{\mathrm{L}_{1}} \times 100 \%,
$$


where $X_{s}$ is the SRX fraction, $L_{1 L}$ is the LAGB content at the breakpoint $(\mu \mathrm{m})$, and $\mathrm{L}_{\mathrm{yL}}$ is the LAGB content after the holding time $(\mu \mathrm{m})$.

\subsubsection{The Determination of $\mathrm{L}_{1 \mathrm{~L}}$}

According to the first-pass thermal compression curve, the LAGB content reduction from the peak point to the breakpoint can be obtained by the CDRX fraction, so the value of $\mathrm{L}_{1 \mathrm{~L}}$ can be determined by the following equation.

$$
\mathrm{L}_{\mathrm{L}}=\mathrm{L}_{\mathrm{P}_{\mathrm{L}}}-\mathrm{X}_{\mathrm{C}^{*} \mathrm{~L}_{\mathrm{L}^{\prime}}}
$$

where $X_{c}$ is the first-pass CDRX fraction, and its value in different hot deformation conditions can be obtained from the author's previously published article [34], and $L_{P L}$ is the LAGB content at the peak point $(\mu \mathrm{m})$, and its value can be obtained by a reduction in the total GB and HAGB content at the peak point. Based on the microscopic transformation mechanism, the HAGB content for the peak point is equal to that of the initial state, because the peak point appears before the occurrence of DRX, so $L_{P L}$ can be expressed as follows:

$$
\mathrm{L}_{\mathrm{P}_{\mathrm{L}}}=\mathrm{L}_{\mathrm{p}}-\mathrm{L}_{\mathrm{OH}}
$$

where $L_{p}$ is the total GB content of the peak point $(\mu \mathrm{m})$, and its value can be obtained from the linear relationship between the GB content and flow stress. $\mathrm{L}_{0 \mathrm{H}}$ is the content of the HAGB in the initial state $(\mu \mathrm{m})$.

\subsubsection{The Determination of $\mathrm{L}_{\mathrm{y}}$}

After the insulation stage, the LAGB content was obtained by the reduction between the total GB and HAGB content at the yield point of the second pass, and can be expressed as:

$$
\mathrm{L}_{\mathrm{yL}}=\mathrm{L}_{\mathrm{y}}-\mathrm{L}_{\mathrm{yH}}
$$

where $L_{y}$ is the total GB content after the thermal insulation stage $(\mu \mathrm{m})$, and its value can be obtained from the linear relationship between GB content and the flow stress. $\mathrm{L}_{\mathrm{yH}}$ is the content of HAGB content after the thermal insulation stage $(\mu \mathrm{m})$. According to Figure $3 \mathrm{c}$, the HAGB content at this point is approximately equal to the value at the peak point of the second pass, which can be regarded as the corresponding equivalent HAGB content $\left(\mathrm{L}_{2 \mathrm{H}}^{\prime}\right)$. Similarly, $\mathrm{L}_{\mathrm{yH}}$ can be determined based on the CDRX fraction, and the expression is as follows.

$$
\mathrm{L}_{\mathrm{yH}}=\mathrm{L}_{2}^{\prime}-\left(\mathrm{L}_{1 \mathrm{~L}}-\mathrm{X}_{\mathrm{Cq}} \cdot \mathrm{L}_{\mathrm{pL}}\right)
$$

where $\mathrm{L}_{2}^{\prime}$ is the total GB content at the equivalent point $(\mu \mathrm{m})$, and its value can be obtained from the linear relationship between the GB content and flow stress.

Based on the steps above, the SRX fraction under different thermal deformation parameters can be obtained, and the results are shown in Figure 7. As presented in Figure 6, the SRX fraction ranges from $5 \%$ to $40 \%$ under different deformation conditions, indicating that the SRX marked by the disappearance of the sub-grain boundary occurs. It has, however, was proven to be incomplete static recrystallization because of the small value. Moreover, it can be seen that the SRX fraction increased with the increase in strain rate and insulation time, while it decreased with the increase in temperature and strain, which is consistent with the conclusions of the step ratio above. The numerical differences of the two description methods present two different perspectives to describe the static softening behavior; the former is more inclined to use the increasing rate of the HAGB, while the latter uses the reduction rate of the LAGB. As the ratio of the HAGB generation and the disappearance of LAGB cannot be 1:1 during SRX, it will lead to a deviation between the two methods. As SRX is usually marked by the complete disappearance of the sub-structures, it is more accurate to describe the SRX fraction with the reduction rate of LAGB. 


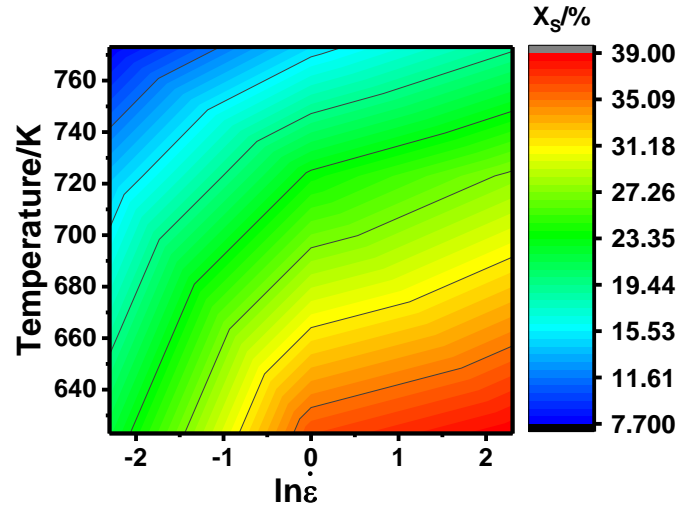

(a)

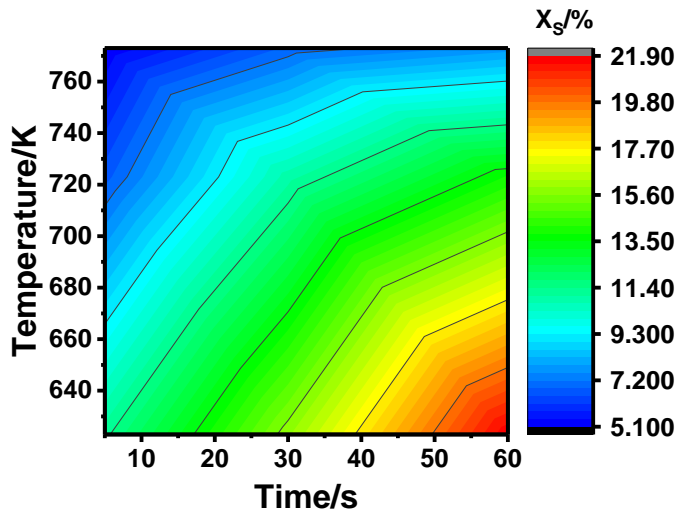

(b)

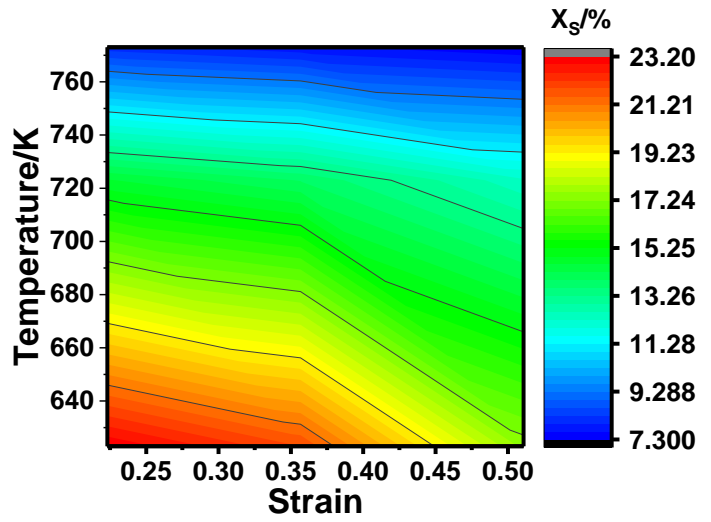

(c)

Figure 7. Static recrystallization fraction under the deformation condition of different temperatures and (a) $\ln \dot{\varepsilon}$, (b) time, and (c) strain.

\subsection{Modified SRX Kinetics}

Generally, the SRX kinetics is expressed by the Avrami type equation, as shown below [38-40].

$$
X_{S}=1-\exp \left[-0.693 \cdot\left(\frac{t}{t_{0.5}}\right)^{n}\right]
$$

where $X_{s}$ is SRX fraction, $t$ is the time $(s), t_{0.5}$ is the time when $50 \%$ recrystallization occurs, and $\mathrm{n}$ is the material parameter.

\subsubsection{Determination of $n$}

By taking the logarithm of Equation (8) twice consecutively, the following formula can be obtained.

$$
\ln \left[\ln \left(\frac{1}{1-X_{S}}\right)\right]=\ln 0.693+n \ln t-n \ln t_{0.5}
$$

The relationship between $\ln \left[\ln \left(\frac{1}{1-X_{S}}\right)\right]$ and $\operatorname{lnt}$ is shown in Figure 8 . The value of $\mathrm{n}$ can be obtained by the average slope. By linear regression analysis, $n=0.251$ was obtained. 


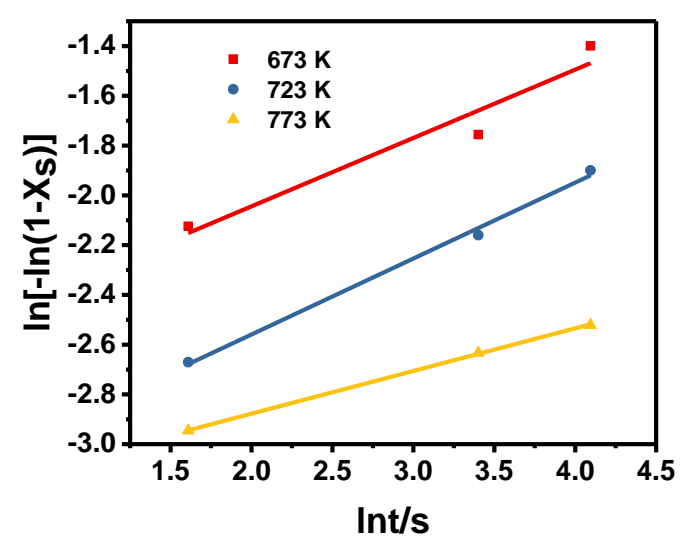

Figure 8. The relationship between $\ln \left[-\ln \left(1-X_{S}\right)\right]$ and $\operatorname{lnt}$.

\subsubsection{Determination of $t_{0.5}$}

$\mathrm{t}_{0.5}$ was determined to be related to the strain rate, deformation temperature, pre-deformation amount, thermal insulation temperature, time, etc., and a mathematical relationship was established with some of them. In this paper, all of these factors were taken into consideration for establishing a comprehensive mathematical relation, as shown below:

$$
\mathrm{t}_{0.5}=\mathrm{a} \cdot \dot{\varepsilon}^{\mathrm{b}} \cdot \varepsilon^{\mathrm{c}} \cdot \exp \left(\frac{k \mathrm{k}_{\mathrm{d}}}{\mathrm{RT}_{\mathrm{d}}}\right) \cdot \exp \left(\frac{\mathrm{mQ}_{\mathrm{a}}}{\mathrm{RT}_{\mathrm{a}}}\right),
$$

where $a, b, c, k$, and $m$ are the material parameters; $\dot{\varepsilon}$ is the strain rate; $\varepsilon$ is the strain; $T_{d}$ is deformation temperature; $T_{a}$ is annealing temperature; $R$ is the gas constant; and $Q_{d}$ and $Q_{a}$ are the dynamic and static thermal activation energies $(\mathrm{kJ} / \mathrm{mol})$, respectively. In this paper, the temperatures $\left(T_{d}\right.$ and $\left.T_{a}\right)$ were consistent because of the isothermal compression and insulation process. Therefore, Equation (10) can be simplified as follows:

$$
\mathrm{t}_{0.5}=\mathrm{a} \cdot \dot{\varepsilon}^{\mathrm{b}} \cdot \varepsilon^{\mathrm{c}} \cdot \exp \left(\frac{k \mathrm{k}_{\mathrm{d}}}{\mathrm{RT}_{\mathrm{d}}}\right) \cdot \exp \left(\frac{\mathrm{mQ}_{\mathrm{a}}}{\mathrm{RT}_{\mathrm{a}}}\right),
$$

where $Q_{m}$ is the equivalent thermal activation energy $(\mathrm{kJ} / \mathrm{mol})$, and its expression is $Q_{m}=k_{d}+m Q_{a}$. By taking the logarithm of Equation (11), the following equation is obtained.

$$
\operatorname{lnt}_{0.5}=\ln \mathrm{a}+\mathrm{bln} \dot{\varepsilon}+\operatorname{cln} \varepsilon+\frac{\mathrm{Q}_{\mathrm{m}}}{\mathrm{RT}},
$$

The relationship between $\operatorname{lnt}_{0.5}$ and $\ln \varepsilon, \ln \varepsilon$, and $1 / \mathrm{T}$ are shown in Figure 9. Using linear regression, the values of $b, c, Q_{m}$ can be obtained by the average slope, and the results are shown in Table 2 . The value of $\ln$ a can be obtained by substituting the obtained values into Equation (12).

Table 2. The values of the material parameters.

\begin{tabular}{ccccc}
\hline Parameters & $\mathbf{b}$ & $\mathbf{c}$ & $\mathbf{Q}_{\mathbf{m}}$ & $\operatorname{lna}$ \\
\hline Values & -0.703 & 2.835 & $-98.317 \times 10^{3}$ & 28.567 \\
\hline
\end{tabular}

In summary, the modified SRX kinetics of the $\mathrm{Al} 2219$ alloy were established, and its expression is as follows:

$$
\left\{\begin{array}{c}
\mathrm{X}_{\mathrm{S}}=1-\exp \left[-0.3693 \cdot\left(\frac{\mathrm{t}}{\mathrm{t}_{0.5}}\right)^{0.251}\right] \\
\mathrm{t}_{0.5}=2.356 \times 10^{17} \cdot \dot{\varepsilon}^{-0.703} \cdot \varepsilon^{2.835} \cdot \exp \left(\frac{-98.317 \times 10^{3}}{\mathrm{RT}}\right)
\end{array},\right.
$$


To verify the accuracy of the established model, the experimental and simulated values under different deformation parameters are compared in Figure 10. It can be observed that the overall recrystallization fraction was within $40 \%$ in the given conditions, and the experimental and simulated data regularity were similar. As shown in Figure 10, the simulated and experimental values were in good agreement with $\mathrm{R}^{2}=0.903$ and $\mathrm{AARE}=13.7 \%$, which indicates that the model was accurate and could be used to predict the SRX fraction under prescribed conditions.

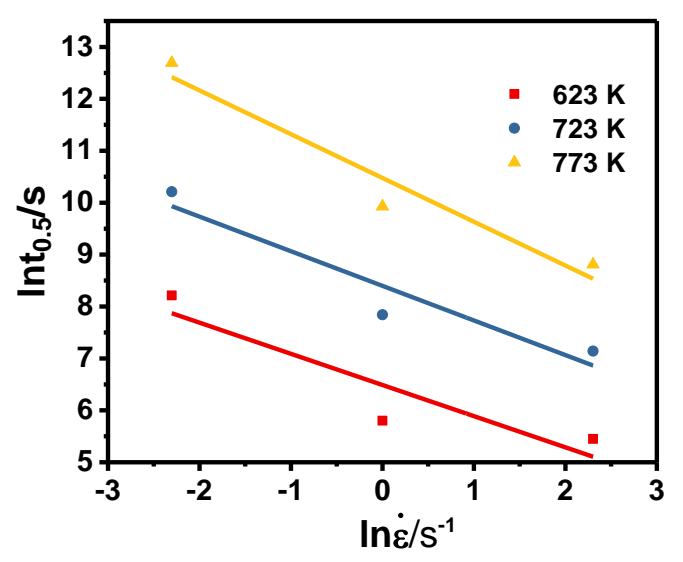

(a)

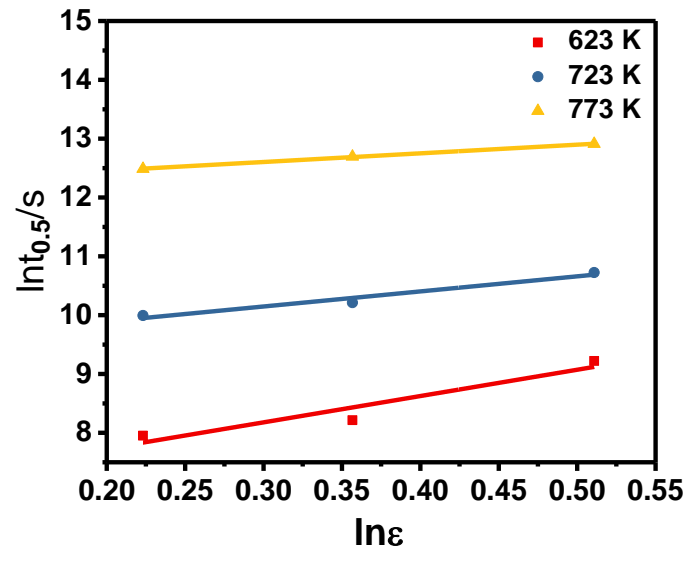

(b)

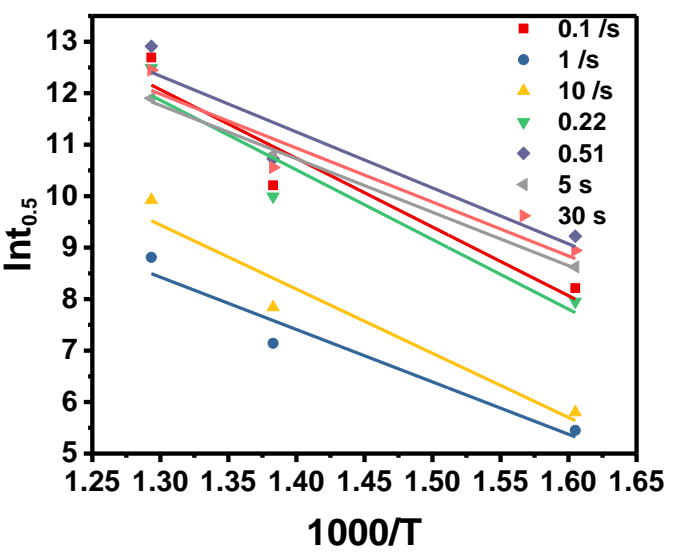

(c)

Figure 9. The relationship between $\operatorname{lnt} t_{0.5}$ and (a) $\ln \dot{\varepsilon},(\mathbf{b}) \ln \varepsilon$, and (c) $1000 / \mathrm{T}$.

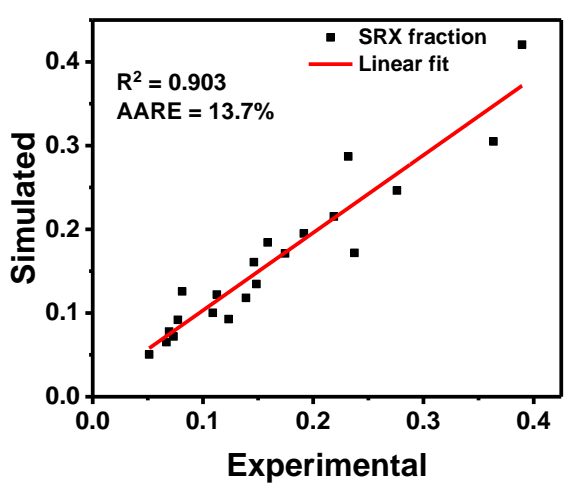

Figure 10. Comparison of the simulated and experimental values of the SRX fraction under different conditions. 


\section{Conclusions}

In this paper, the static softening mechanism of the Al 2219 alloy was studied based on the double-pass thermal compression test, and a modified SRX kinetic model was established by the new expression of the SRX fraction. The specific conclusions are as follows:

- The static softening mechanism of the Al 2219 alloy is mainly SRV and incomplete SRX, which is determined via step phenomenon and microstructure detection;

- The step rate of the first- and second-pass are represented by the equivalent dynamic recrystallization fraction in the form of flow stress, which increases with the increase in strain rate and isothermal insulation time, while it decreases with the increase in temperature and strain;

- A new expression for the SRX fraction is proposed based on the reduction rate of the sub-grain boundary. Compared with the traditional stress method, the new expression method is derived from the micro perspective, and the data obtained from experiment and EBSD observation are more real and effective, which is feasible in theory and practice and is applicable to samples of all processing states. The dependent rule on deformation parameters is consistent with the step rate, and it is of physical significance;

- $\quad$ The SRX kinetic model considering all of the deformation factors established in this paper has good modeling and prediction performance under the given deformation conditions, with a correlation coefficient of 0.903 and a relative error of $13.7 \%$, and the method can be applied to other similar materials.

Author Contributions: Conceptualization, L.L. and Y.W.; methodology, L.L.; software, L.L.; validation, H.G., F.D., and H.Y.; formal analysis, L.L.; investigation, L.L.; resources, H.G.; data curation, F.D.; writing (original draft preparation), L.L.; writing (review and editing), Y.W. and A.S.A. Ahmad; visualization, H.Y.; supervision, Y.W.; project administration, H.G.; funding acquisition, Y.W. All authors have read and agreed to the published version of the manuscript.

Funding: The research was funded by the National Natural Science Foundation of China (grant numbers: 51327902, U1637601, and 51975596), the Pre-research Project of Civil Aerospace (grant number: B0109), and the Fundamental Research Funds for the Central Universities of Central South University (grant number: 502221801).

Conflicts of Interest: The authors declare no conflict of interest.

\section{References}

1. He, H.; Yi, Y.; Huang, S.; Zhang, Y. An improved process for grain refinement of large $2219 \mathrm{Al}$ alloy rings and its influence on mechanical properties. J. Mater. Sci. Technol. 2019, 35, 55-63. [CrossRef]

2. Guo, W.; Yi, Y.; Huang, S.; Mao, X.; Fang, J.; He, H.; Hu, B. Effects of deformation temperature on the evolution of second-phase and mechanical properties of large 2219 Al-Cu alloy rings. Mater. Charact. 2020, 160, 110094. [CrossRef]

3. Zhang, D.; Zhao, Y.; Dong, M.; Wang, G.; Wu, A.; Shan, J.; Meng, D.; Liu, X.; Song, J.; Zhang, Z. Effects of weld penetration on tensile properties of 2219 aluminum alloy TIG-welded joints. Trans. Nonferrous Met. Soc. China 2019, 29, 1161-1168. [CrossRef]

4. Zhou, Y.; Lin, X.; Kang, N.; Huang, W.; Wang, J.; Wang, Z. Influence of travel speed on microstructure and mechanical properties of wire + arc additively manufactured 2219 aluminum alloy. J. Mater. Sci. Technol. 2020, 37, 143-153. [CrossRef]

5. Liu, T.; Zhan, X.; Zhao, Y.; Bai, M.; Gong, X. Study on 2219 aluminum alloy T-joint during dual laser-beam bilateral synchronous welding: Effect of the welding speed and incident beam angle on grain morphology. Opt. Laser Technol. 2019, 119, 105594. [CrossRef]

6. Zeng, X.; Fan, X.G.; Li, H.W.; Zhan, M.; Li, S.H. Grain morphology related microstructural developments in bulk deformation of 2219 aluminum alloy sheet at elevated temperature. Mater. Sci. Eng. A 2019, 760, 328-338. [CrossRef]

7. Li, H.; Zou, J.; Yao, J.; Peng, H. The effect of TIG welding techniques on microstructure, properties and porosity of the welded joint of 2219 aluminum alloy. J. Alloy. Compd. 2017, 727, 531-539. [CrossRef] 
8. Zhang, D.; Wang, G.; Wu, A.; Zhao, Y.; Li, Q.; Liu, X.; Meng, D.; Song, J.; Zhang, Z. Study on the inconsistency in mechanical properties of 2219 aluminium alloy TIG-welded joints. J. Alloy. Compd. 2019, 777, 1044-1053. [CrossRef]

9. He, H.; Yi, Y.; Huang, S.; Guo, W.; Zhang, Y. Effects of thermomechanical treatment on grain refinement, second-phase particle dissolution, and mechanical properties of $2219 \mathrm{Al}$ alloy. J. Mater. Process. Technol. 2020, 278, 116506. [CrossRef]

10. Lu, Y.; Wang, J.; Li, X.; Chen, Y.; Zhou, D.; Zhou, G.; Xu, W. Effect of pre-deformation on the microstructures and properties of 2219 aluminum alloy during aging treatment. J. Alloy. Compd. 2017, 699, 1140-1145. [CrossRef]

11. Lu, Y.; Wang, J.; Li, X.; Li, W.; Li, R.; Zhou, D. Effects of pre-deformation on the microstructures and corrosion behavior of 2219 aluminum alloys. Mater. Sci. Eng. A 2018, 723, 204-211. [CrossRef]

12. Lin, Y.C.; Wu, Q.; He, D.-G.; Zhu, X.-H.; Liu, D.; Li, X.-H. Effects of solution time and cooling rate on microstructures and mechanical properties of $2219 \mathrm{Al}$ alloy for a larger spun thin-wall ellipsoidal head. J. Mater. Res. Technol. 2020, 9, 3566-3577. [CrossRef]

13. Nie, X.; Dong, S.; Wang, F.; Jin, L.; Zhang, Z.; Dong, J.; Wang, Y. Flow behavior and formability of hot-rolled Mg-8Gd-3Y alloy under double-pass isothermal compression. J. Mater. Process. Technol. 2020, 275, 116328. [CrossRef]

14. Nie, X.; Dong, S.; Wang, F.; Jin, L.; Dong, J. Effects of holding time and Zener-Hollomon parameters on deformation behavior of cast Mg-8Gd-3Y alloy during double-pass hot compression. J. Mater. Sci. Technol. 2018, 34, 2035-2041. [CrossRef]

15. Zhang, S.Z.; Li, M.M.; Chen, L.Q. Flow behavior and microstructure evolution during double-hit compression of Ti-5.6Al-4.8Sn-2Zr-1Mo-0.35Si-0.7Nd titanium alloy. Mater. Sci. Eng. A 2013, 564, 317-323. [CrossRef]

16. Chen, K.; Tang, J.; Jiang, F.; Teng, J.; Fu, D.; Zhang, H. The role of various Zr additions in static softening behavior of $\mathrm{Al}-\mathrm{Zn}-\mathrm{Mg}-\mathrm{Cu}$ alloys during interval holding of double-stage hot deformation. J. Alloy. Compd. 2019, 792, 1112-1121. [CrossRef]

17. Wang, X.; Chandrashekhara, K.; Buchely, M.F.; Lekakh, S.; Van Aken, D.C.; O'Malley, R.J.; Ridenour, G.W.; Scheid, E. Experiment and simulation of static softening behavior of alloyed steel during round bar hot rolling. J. Manuf. Process. 2020, 52, 281-288. [CrossRef]

18. Barbosa, J.V.; Melo, T.M.F.; Santos, D.B. Dynamic and static softening behavior of a titanium added ultra-low carbon steel during hot and warm deformation. J. Mater. Res. Technol 2020, 9, 2810-2817. [CrossRef]

19. Jiang, F.; Zurob, H.S.; Purdy, G.R.; Zhang, H. Static softening following multistage hot deformation of 7150 aluminum alloy: Experiment and modeling. Mater. Sci. Eng. A 2015, 648, 164-177. [CrossRef]

20. Pouraliakbar, H.; Pakbaz, M.; Firooz, S.; Jandaghi, M.R.; Khalaj, G. Study on the dynamic and static softening phenomena in $\mathrm{Al}-6 \mathrm{Mg}$ alloy during two-stage deformation through interrupted hot compression test. Measurement 2016, 77, 50-53. [CrossRef]

21. Llanos, L.; Pereda, B.; Lopez, B.; Rodriguez-Ibabe, J.M. Hot deformation and static softening behavior of vanadium microalloyed high manganese austenitic steels. Mater. Sci. Eng. A 2015, 651, 358-369. [CrossRef]

22. Jin, Z.; Yin, K.; Yan, K.; Wu, D.; Liu, J.; Cui, Z. Finite element modelling on microstructure evolution during multi-pass hot compression for AZ31 alloys using incremental method. J. Mater. Sci. Technol. 2017, 33, 1255-1262. [CrossRef]

23. Zhao, M.; Huang, L.; Zeng, R.; Wen, D.; Su, H.; Li, J. In-situ observations and modeling of static recrystallization in $300 \mathrm{M}$ steel. Mater. Sci. Eng. A 2019, 765, 138300. [CrossRef]

24. Xu, X.; Li, J.; Li, W.; Liu, Q.; Liu, D.; Wang, X.; Wang, J.; Shang, C.; Misra, R.D.K. Experimental and theoretical study on static recrystallization of a low-density ferritic steel containing 4 mass\% aluminum. Mater. Des. 2019, 180, 107924. [CrossRef]

25. Bo, G.; Jiang, F.; Su, H.; Wu, L.; Teng, J.; Fu, D.; Zhang, H. Static softening behavior and modeling of an $\mathrm{Al}-\mathrm{Cu}-\mathrm{Mg}-\mathrm{Zr}$ alloy with various pre-precipitation microstructures during multistage hot deformation. Mater. Sci. Eng. A 2020, 778, 139094. [CrossRef]

26. Jiang, F.; Zhang, H.; Li, L.; Chen, J. The kinetics of dynamic and static softening during multistage hot deformation of 7150 aluminum alloy. Mater. Sci. Eng. A 2012, 552, 269-275. [CrossRef]

27. Tang, J.; Zhang, H.; Teng, J.; Fu, D.; Jiang, F. Effect of Zn content on the static softening behavior and kinetics of Al-Zn-Mg-Cu alloys during double-stage hot deformation. J. Alloy. Compd. 2019, 806, 1081-1096. [CrossRef] 
28. Yanagida, A.; Yanagimoto, J. Formularization of softening fractions and related kinetics for static recrystallization using inverse analysis of double compression test. Mater. Sci. Eng. A 2008, 487, 510-517. [CrossRef]

29. Shen, W.; Zhang, C.; Zhang, L.; Xu, Q.; Cui, Y.; Xu, Y. A modified Avrami equation for kinetics of static recrystallization of $\mathrm{Nb}-\mathrm{V}$ microalloyed steel: Experiments and numerical simulation. Vacuum 2018, 150, 116-123. [CrossRef]

30. Zhang, H.; Lin, G.Y.; Peng, D.S.; Yang, L.B.; Lin, Q.Q. Dynamic and static softening behaviors of aluminum alloys during multistage hot deformation. J. Mater. Process. Technol. 2004, 148, 245-249. [CrossRef]

31. Liu, L.; Wu, Y.; Gong, H.; Li, S.; Ahmad, A.S. A Physically Based Constitutive Model and Continuous Dynamic Recrystallization Behavior Analysis of 2219 Aluminum Alloy during Hot Deformation Process. Materials 2018, 11, 1443. [CrossRef] [PubMed]

32. Lin, Q.; Dong, W.; Li, Y.; Zhang, H.; Wang, Z. Microstructure Simulation of 2519 Aluminum Alloy in Multi-pass Hot Compression Process. Procedia. Eng 2014, 81, 1259-1264. [CrossRef]

33. Zeng, R.; Huang, L.; Li, J.; Li, H.; Zhu, H.; Zhang, X. Quantification of multiple softening processes occurring during multi-stage thermoforming of high-strength steel. Int. J. Plast. 2019, 120, 64-87. [CrossRef]

34. Liu, L.; Wu, Y.; Gong, H.; Dong, F.; Ahmad, A.S. Modified kinetic model for describing continuous dynamic recrystallization behavior of Al 2219 alloy during hot deformation process. J. Alloy. Compd. 2020, 817, 153301. [CrossRef]

35. Fernández, A.I.; López, B.; Rodríguez-Ibabe, J.M. Relationship between the austenite recrystallized fraction and the softening measured from the interrupted torsion test technique. Scr. Mater. 1999, 40, 543-549. [CrossRef]

36. Zurob, H.S.; Hutchinson, C.R.; Brechet, Y.; Purdy, G.R. Rationalization of the softening and recrystallization behaviour of microalloyed austenite using mechanism maps. Mater. Sci. Eng. A 2004, 382, 64-81. [CrossRef]

37. Lin, Y.C.; Li, L.-T.; Xia, Y.-C. A new method to predict the metadynamic recrystallization behavior in 2124 aluminum alloy. Comput. Mater. Sci. 2011, 50, 2038-2043. [CrossRef]

38. Najafizadeh, A.; Jonas, J.J.; Stewart, G.R.; Poliak, E.I. The strain dependence of postdynamic recrystallization in $304 \mathrm{H}$ stainless steel. Metall. Mater. Trans. A 2006, 37, 1899-1906. [CrossRef]

39. Dong, H.; Cai, D.; Zhao, Z.; Wang, Z.; Wang, Y.; Yang, Q.; Liao, B. Investigation on static softening behaviors of a low carbon steel under ferritic rolling condition. J. Mater. Eng. Perform. 2010, 19, 151-154. [CrossRef]

40. Furu, T.; Shercliff, H.R.; Baxter, G.J.; Sellars, C.M. The influence of transient deformation conditions on recrystallization during thermomechanical processing of an Al-1\% Mg alloy. Acta Mater. 1999, 47, 2377-2389. [CrossRef]

(C) 2020 by the authors. Licensee MDPI, Basel, Switzerland. This article is an open access article distributed under the terms and conditions of the Creative Commons Attribution (CC BY) license (http://creativecommons.org/licenses/by/4.0/). 